\title{
Patient Satisfaction after Primary knee Arthroplasty in Indian Scenario
}

\author{
Chandra Prakash Pal* and Yajuvendra Kumar Sharma \\ Department of Orthopedics, Sarojini Naidu Medical College, India \\ Submission: May 22, 2018; Published: June 18, 2018
}

*Corresponding author: Chandra Prakash Pal, Asst. Professor and Head, Department of Orthopedics, Sarojini Naidu Medical College, Agra-9634031500, India, Email: drcportho@gmail.com

\begin{abstract}
Introduction: Arthritis is one of the leading causes of disability in India and Osteoarthritis (OA) is the most common type of arthritis found in Indian population. Total knee arthroplasty reliably reduces pain and improves health-related quality of life. Dissatisfaction still remains in some patients even after excellent results. The purpose of this study was to assess muscle strength, range of motion (ROM), and functional performance of patients prospectively from before to after TKA.
\end{abstract}

Research method: This was a prospective cohort study of twenty three patients undergoing TKA, evaluated at 2 weeks preoperatively, as well as at 1, 3, and 6 months postoperatively. Patients were evaluated by WOMAC score and a question for satisfaction: How much satisfied he/ she is with his arthroplasty? Answer was asked in dissatisfied, neutral, satisfied at follow up at 6 months.

Results: The mean WOMAC score was better after 6 months postoperatively from preoperatively. Out of twenty three, 78.26\% (18) were satisfied, $17.40 \%$ (4) were neutral and 4.34(1) was dissatisfied.

Discussion: TKA has been shown to be safe and effective in addressing end-stage osteoarthritis of the knee. But not all patients are satisfied after this procedure. Various studies have noted that only $82-89 \%$ patients express satisfaction $[7,8,9]$. According to our study patient satisfaction after primary total knee arthroplasty was $78.26 \%$ and a significant improvement in WOMAC score.

Keywords: TKA; Patients satisfaction; Indian patients

\section{Introduction}

Arthritis is one of the leading causes of disability in India and Osteoarthritis $(\mathrm{OA})$ is the most common type of arthritis found in Indian population. Osteoarthritis of the knee is a relatively common condition that affects approximately $10 \%$ of the general population above the age of 55 years [1]. The primary indication for TKA is to relieve pain caused by severe arthritis, with or without significant deformity. It is one of the most successful and effective surgical options to reduce pain and restore function for patients with severe osteoarthritis [2,3]. Flexion contracture of more than 20 degrees, significantly hampers gait and difficulty with regaining extension frequently need operative intervention. Total knee arthroplasty reliably reduces pain and improves health-related quality of life. Dissatisfaction still remains in some patients even after excellent results. The purpose of this study was to assess muscle strength, range of motion (ROM), and functional performance of patients prospectively from before to after TKA.

\section{Research Method}

This was a prospective cohort study of twenty three patients undergoing TKA, evaluated at 2 weeks preoperatively, as well as at 1,3 , and 6 months postoperatively. Prosthesis used was cruciate sacrificing. The 6-month time point was chosen because patients recovering from TKA typically plateau in strength and functional gains by this time point. Patients were included if they were between the ages of 50 and 85 years and were undergoing a primary unilateral TKA for end-stage knee OA. Patients undergoing TKA were excluded if they had uncontrolled hypertension, uncontrolled diabetes, BMI greater than $35 \mathrm{~kg} /$ $\mathrm{m} 2$, significant neurologic impairments, significant contra lateral knee OA (as defined by pain greater than $4 / 10$ with activity), or other unstable, lower extremity orthopedic conditions. Patients were evaluated by WOMAC score and a question for satisfaction: How much satisfied he/she is with his arthroplasty? Answer was asked in dissatisfied, neutral, satisfied at follow up at 6 months.

\section{Results}

The mean WOMAC score was better after 6 months postoperatively from preoperatively. The mean 6 months WOMAC pain score was $81.6 \pm 9.3$ with a change score of $36.7 \pm$ 18.4. The mean 6 months WOMAC joint stiffness score was 70.3 \pm 8.4 with a change score of $29.8 \pm 12.4$. The mean 6 months WOMAC function score was $76.7 \pm 9.7$, representing an average 
improvement of $34.2 \pm 18.5$. Out of twenty three, $78.26 \%$ (18) were satisfied, $17.40 \%$ (4) were neutral and 4.34(1) was dissatisfied.

\section{Discussion}

Osteoarthritis of the knee is much prevalent condition in Indian population. It can progress to a point where it is debilitating [4] It adversely affects the patient's quality of life due to pain and decreased function $[5,6]$. While there are many modes of treatment, including conservative and surgical management, the definitive method of treatment is joint replacement. In this regard, TKA has been shown to be safe and effective in addressing end-stage osteoarthritis of the knee. This surgical procedure has become more common due to its effectiveness in alleviating pain and improving function, and will continue to play a key role in the management of osteoarthritis. But not all patients are satisfied after this procedure. Various studies have noted that only 82-89\% patients express satisfaction [7-9]. According to our study patient satisfaction after primary total knee arthroplasty was $78.26 \%$ and a significant improvement in WOMAC score.

\section{Conclusion}

Study signifies that patients after arthroplasty have significantly better WOMAC score than before and significant satisfaction rate of patients supporting other studies. It would be wise for surgeons to discuss with patient his expectations before TKA surgery to assure that they could be met or not.

\section{References}

1. Petersson IF (1996) Occurrence of osteoarthritis of the peripheral joints in European populations. Ann Rheum Dis 55(9): 659-661.

2. Riley LH Jr (1985) Total knee arthroplasty. Clin Orthop Relat Res 192: 34-39.

3. Kane RL, Saleh KJ, Wilt TJ, Bershadsky B (2005) The functional outcomes of total knee arthroplasty. J Bone Joint Surg Am 87(8): 17191724 .

4. Nguyen US, Zhang Y, Zhu Y, Niu J, Zhang B, et al. (2011) Increasing prevalence of knee pain and symptomatic knee osteoarthritis: survey and cohort data. Ann Intern Med 155(11): 725-732.

5. Felson DT, Naimark A, Anderson J, Kazis L, Castelli W, et al. (1987) The prevalence of knee osteoarthritis in the elderly. The Framingham Osteoarthritis Study. Arthritis Rheum 30: 914-918.

6. Felson DT (1990) The epidemiology of knee osteoarthritis: results from the Framingham Osteoarthritis Study. Semin Arthritis Rheum 20(3 Suppl 1): 42-50.

7. Anderson JG, Wixson RL, Tsai D, Stulberg SD, Chang RW (1996) Functional outcome and patient satisfaction in total knee patients over the age of 75. J Arthroplasty 11(7): 831-840.

8. Dillman D (2000) Mail and Electronic Surveys: The Tailored Design Method. Wiley, New York, USA.

9. Dunbar MJ, Robertsson O, Ryd L, Lidgren L (2001) Appropriate questionnaires for knee arthroplasty. Results of a survey of 3600 patients from the Swedish Knee Arthroplasty Registry. J Bone Joint Surg Br 83(3): 339-344.

\section{Your next submission with Juniper Publishers} will reach you the below assets

- Quality Editorial service

- Swift Peer Review

- Reprints availability

- E-prints Service

- Manuscript Podcast for convenient understanding

- Global attainment for your research

- Manuscript accessibility in different formats

( Pdf, E-pub, Full Text, Audio)

- Unceasing customer service

Track the below URL for one-step submission https://juniperpublishers.com/online-submission.php 